\title{
Battle Injuries Of The Rectum: Options For The Field Surgeon
}

\author{
C MacFarlane, CJ Vaizey, CA Benn
}

C MacFarlane HonsBA $\mathrm{BSc}$ (Hons) MBChB

MMed(Surg) PhD

FRCSEd FRCSEng

FACS FCS(SA)

FACEM(Hon) FFAEM

MRACMA DMCC

FRAeS

Gauteng Provincial

Government Emergency

Medical Services,

Hon. Lecturer,

Johannesburg Hospital

Trauma Unit and Dept.

Surgery,University of

the Witwatersrand,

Johannesburg,

PO Box8311,

Halfway House, 1685,

South Africa.

CJ Vaizey $M D$

FRCS(Gen) FCS(SA)

Consultant Colorectal

Surgeon

The Middlesex

Hospital, Mortimer

Street,London.

CA Benn MBBCh

FCS(SA) DIP

PEC(SA)

Consultant Surgeon

Chris Hani

Baragwanath Hospital and University of the

Witwatersrand,

Johannesburg,

South Africa.

\begin{abstract}
Historically, battle wounds of the rectum have had high mortality and morbidity. This has improved greatly over several decades as a result of battle experience. This article highlights the value of civilian gunshot experience and its possible use in the military setting. The standard principles of rectal examination, followed by proctosigmoidoscopy after initial resuscitation, remain unchanged. Thereafter, the surgical decisions are made at laparotomy. Rectal injuries commonly have other injuries in association which must also be dealt with. In the stable patient rectal repair may be possible. Where repair is hazardous due to extensive injury (rectum or adjacent structures), the well-proven protective colostomy is used. A loop colostomy with or without distal closure is effective and is used to protect most injuries; possible exceptions being injuries dealt with early, in which there is minimal contamination and repair is easy. Presacral drainage can generally be reserved for severely destructive wounds or those in which repair has not been done. Rectal washout remains an option in patients with inspissated faeces. The basic military surgical principles remain valid, their extent and degree of implementation depending on the anatomical location of injury, degree of damage and any delay in presentation to surgery.
\end{abstract}

\section{Introduction}

Problems exist in the practice of battle surgery today. Rapid deployment military forces may be required to mobilise quickly, with minimal initial heavy support. A field surgical team deploying with such a force will not be a large, multiple specialty unit, and may only include one surgeon in the critical first period. As modern surgical training becomes more and more super-specialised, the widely trained general or military surgeon of the past is becoming a rarity. Guidelines to assist surgeons in this situation are essential. In the United Kingdom, the situation is compounded by the fact that gunshot wounds are relatively rare, so that any individual surgeon is likely to be relatively inexperienced in this area unless he or she has had overseas exposure in areas where penetrating abdominal trauma is common.

Historically, battle wounds of the rectum have a relatively high mortality and morbidity. In World War I, the mortality from penetrating rectal injury was $50 \%$ (1). By World War II the mortality had been reduced to $30 \%$ and this was attributed to the provision of a diverting colostomy (2). In the Vietnam conflict, mortality was down to $14 \%$, with the addition of presacral drainage and rectal washouts (3). A recent series from the Balkans quotes a mortality rate of around $10 \%$ (4). Standard military surgery management doctrine has been rectal repair, defunctioning colostomy, rectal washout and pre-sacral drainage.

\section{Diagnosis}

In attending to a casualty with a gunshot wound, attention is first directed to resuscitation and dealing with lifethreatening emergencies. Primary and secondary survey may reveal evidence of abdominal penetration or an "acute abdomen", which could be due to injury of several intra-abdominal structures, including the rectum. The presence of blood on digital rectal examination is an absolute indication for surgery (5). It should be followed by proctosigmoidoscopy, the combined accuracy of these two examinations in predicting rectal injury being $95 \%$ (6). Rigid sigmoidoscopy is an essential part of the examination for penetrating trauma to the buttocks or injury in the region of the pelvis, particularly if it crosses the midline.

If laparotomy is embarked upon, all intraabdominal structures must be sequentially inspected for injury and dealt with according to priority. The surgical rectum begins at the sacral promontory, about 15 centimetres from the anus, where the two antimesenteric taeniae fuse. The intra-abdominal portion can be readily inspected, but accurate assessment of the extra-peritoneal rectum is more difficult. Visualisation of an injury may require mobilisation, but care must be taken not to cause more damage than has already been inflicted by the missile, through relentless pelvic dissection. Rectal injury in the distal part may be presumed from peritoneal penetration, perirectal damage or haematoma and bullet track proximity. Perforation in this area may, of course, have already been noted at proctosigmoidoscopy. 


\section{Pathogenesis - Military Versus Civilian Injuries}

In battle, the wounding agents are usually bullets or metallic fragments of varying velocities. Occasionally, bayonet or fighting knife wounds may be encountered; also crush injuries from vehicular trauma or demolished buildings and fortifications. The high incidence of associated injuries to other structures in the proximity (7), such as the pelvis, small bowel, colon, bladder, urethra and abdominal and pelvic blood vessels, in part explains the high morbidity and mortality.

In most descriptions of gunshot wounds of the rectum the presumption is made that all military wounds are of the "high energy exchange" type and all civilian wounds of the "low energy exchange" type. This is not necessarily so, some military bullet wounds not being characteristic of high velocity injuries; for example bullets which are from a distant weapon and are at the end of their trajectory, or bullets which have passed through vehicles, walls and barricades. Fragment wounds from shells, bombs or grenades can be of a variety of velocities. Similarly, in some parts of the world high velocity weapons are regularly used by civilians involved in criminal activities. The surgeon should concentrate on the injury at hand, irrespective of presumed velocity and available energy of the missile.

As with civilian practice, some of the standard principles of military surgery management of rectal injuries have recently been questioned. As many of the military reports on rectal injuries are anecdotal or based on retrospective analysis of nonrandomised cases, the subject is likely to remain controversial.

\section{Management}

What advice can be given to the noncolorectal specialised surgeon, probably with little experience in gunshot wound management, who finds him or herself in an isolated field surgical team? The military surgeon must be circumspect and selective in considering recommendations from civilian trauma centres.

The military surgeon's casualties are usually fit young people, but many will be in a state of dehydration from sustained physical exertion, battle activity and, possibly, climatic conditions. There are tactical and logistic considerations also. The wounded soldier may have taken a long time to be extracted from combat and evacuated to surgical care. There may be an evacuation policy of transfer reasonably soon after field surgery to base facilities, or, as in a semistatic field surgery unit in peace-keeping operations, there may be a holding policy of various periods of time. All of these factors impact on surgical decisions.

What is not in doubt is that the field surgeon's first task, after appropriate casualty triage, is to perform rapid resuscitation and assessment, dealing with life-threatening situations as they present. All casualties should be commenced on antibiotic therapy on diagnosis of a rectal injury, the duration of this therapy being tailored to the type of injury and degree of faecal contamination.

Thereafter, a decision is taken at laparotomy. The entire abdominal contents are inspected and the various injuries dealt with according to priorities. Haemostasis is the first priority!

Taking a consensus of military surgical doctrine and more recent civilian experience, it may be useful to consider management in terms of anatomy (8). The intraperitoneal wound can be dealt with in a manner similar to that of the sigmoid colon, the simpler wounds being amenable to primary closure and the others requiring protective colostomy. With more complex intraperitoneal wounds and with extra-peritoneal injuries, the military surgeon may be faced with major decisions in four different categories:

1. Repair of the injury

2. Defunctioning stoma

3. Pre-sacral drainage.

4. Rectal washout.

\section{Repair of the injury}

If repair is possible this may be undertaken in the stable casualty. However, this can prove hazardous, particularly in the lower rectum or when the pelvis is distorted by haematoma. Mobilisation of the rectum can result in further injury to, or devascularisation of, the rectum, or in injuries to neighbouring structures. These latter include the ureters and the autonomic nerves responsible for potency. If a simple repair is not possible or if the casualty is unstable and a rapid conclusion to the operation necessary, the rectum may be left open with a covering stoma (9). Transanal repair of a laceration is occasionally possible in selected patients in the hands of experienced colorectal surgeons (10), but, if vigorous anal retraction is necessary to achieve this, serious damage to the anal sphincter mechanism can result. Unless the field surgeon has colorectal experience, transanal procedures are best avoided.

\section{Defunctioning stoma}

Most authors agree on the necessity for a diverting colostomy (9). However, the early injury associated with minimal contamination, which the surgeon has repaired with ease and confidence, may be left unprotected. All other penetrating injuries should be defunctioned.

The most commonly constructed stoma is a sigmoid colostomy; the debate has been whether this needs to be an end colostomy or not to achieve complete defunctioning of the 
rectum. The original military authors stated that end colostomies were mandatory $(3,11)$, but subsequent experience has cast doubt upon this. Some authors have shown that loop colostomies are effective in protecting the distal bowel $(12,13)$. A loop stoma with a closure of the distal end (Figure 1), has the advantage of guaranteed complete defunctioning, at the same time as being as easily reversible as a loop. A Hartmann's type of procedure can result in a difficult closure, but this may be necessary in the unstable casualty where there has been loss of rectosigmoid length and the distal segment is not long enough to reach skin level. The stable casualty may be suitable for a primary repair and defunctioning loop ileostomy. Where there has been a major rectal injury with significant loss or devascularisation of the rectal wall, the possible future need to use the left colon as a neorectum should be kept in mind when positioning and constructing a stoma. It is interesting to note that successful same admission, ie early, colostomy closure for rectal injuries has been undertaken (14). This may be of significance in field surgical teams with a holding policy and capacity.

\section{Pre-sacral drainage}

Military surgical doctrine advocates the use of pre-sacral drainage as standard, utilising an incision between the coccyx and anus and

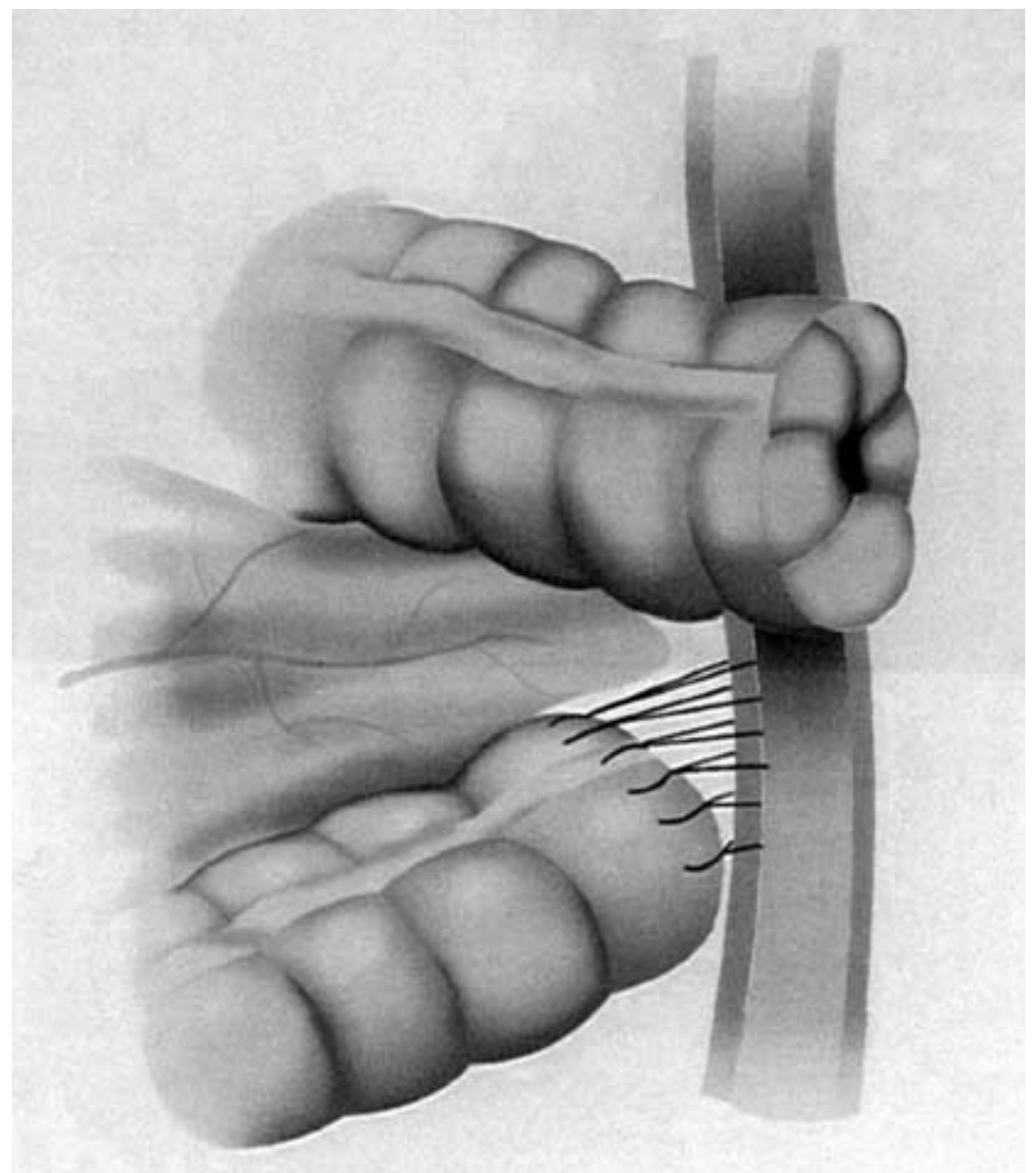

Fig 1. Defunctioning end colostomy with distal end closed but still adjacent to the stoma for easy closure. The distal end can be brought through the stoma site or attached to the abdominal wall next to the stoma as shown. opening up the space between the sacrum and rectum to provide dependent drainage (15). Civilian experience has cast doubt about the need for this practice. Presacral drainage is obviously not of value in intraperitoneal wounds, which can be readily drained via the abdomen. Drainage of an anterior rectal injury by placement of a posterior drain is also of dubious value (16). There is also the possibility of creating more damage and bleeding with a dissection in the area posterior to the rectum.

In civilian practice, the only prospective randomised study of presacral drainage on 48 patients concluded that drainage has no effect on septic complications (16). One retrospective study of 20 patients showed no difference in complications (17), another, including fifty eight patients, concluded that extraperitoneal injuries which are not explored should have presacral drainage (18).

Clearly, there is not yet consensus on this matter. Although pre-sacral drainage is no longer mandatory in the civilian setting, most military recovery facilities will not have the luxury of access to CT scanning and to a radiologist who can insert a pelvic drain post operatively, where necessary. It is advisable to err on the side of caution and insert a drain, especially where there are severely destructive wounds or in those that have not been repaired.

\section{Rectal Washout}

Rectal washouts have been strongly advocated by military surgeons, and are certainly part of the military surgical doctrine. The idea is to wash out potential contaminating and obstructive faecal debris. Again, many of the civilian authors have been unenthusiastic about this technique, some claiming that it forces faecal material out into the perirectal tissues (19). Certainly, the previously favoured adjunct of an anal stretch can be most damaging to the anal sphincter mechanism, with resulting longterm incontinence in some cases. A simple proctoscope inserted into the anal canal at the time of the washout will provide ample outflow.

A retrospective review of forty-seven civilian patients with rectal injury had no mortality, with only one patient receiving a rectal washout (19). Two further retrospective studies of 54 and 28 patients failed to demonstrate a need for washout $(20,21)$. However, two comparative studies of twentyseven and forty-three patients found fewer septic complications occurring in the patients who received a rectal washout (22, 6).

In military practice, Armstrong et al 1973 (23), make the very important point that many wounded soldiers have been dehydrated for some time, the result being that they may have inspissated faeces in the 
rectum amounting to a "faecolith". In such a situation distal rectal washouts would be advisable.

Further intra-operative considerations include the following:

1. Uncontrolled pelvic bleeding

2. Devitalisation or massive destruction of rectal tissues

3. Anal sphincter injury

4. Associated injuries to the urinary tract

\section{Uncontrolled pelvic bleeding}

Entering a pelvic haematoma is a hazardous experience which should be avoided if at all possible. If there is active bleeding of bony origin, pelvic fixation should be a priority. This may not be possible initially in the field and pelvic binding may have to be utilised, recognising the difficulty of this in the presence of a laparotomy. At operation, bleeding may have to be controlled with packing, especially when the civilian luxury of a vascular embolisation service is not available.

\section{Devitalisation or massive destruction of rectal tissues}

It may be necessary to perform an abdomino-perineal resection where there is massive destruction of rectal tissue (24). This is major surgery, which can lead to further bleeding and to injuries to neighbouring structures. Damage control with a defunctioning stoma, pelvic packing and a later return to theatre may be the optimal management for the non-colorectal surgeon or in the unstable patient.

\section{Anal sphincter injury}

The proximity of the anal sphincter muscles makes them an essential consideration in the management of rectal trauma. A diverting stoma will allow for healing of the surrounding tissues and, in most cases, a delayed repair in the hands of an expert will provide the best functional results.

\section{Associated injuries to the urinary tract}

A high index of suspicion $(25,26)$ should lead to early recognition of these injuries. Tissue debridement, a tension-free closure and separation of the urinary and intestinal tracts, form the basis of surgical management. Stoma diversion, rectal washout and adequate drainage are also necessary.

\section{Conclusion}

Thomas et al 1990 (27) advocate the view that a single doctrinal approach may not be justified and that the universal application of all components of those principles may also not be justified. The military surgeon has a degree of choice in the management of battle wounds of the rectum. The management, as indicated above, may depend on the anatomical location of the wound and the degree of damage. The "civilian" type battle wounds allow the options of the various methods outlined, but, if in doubt, or if it is a classical high energy transfer battle wound, the military surgeon is advised to stick to standard military surgical doctrine, irrespective of civilian experience.

\section{References}

1. Wallace C (1917). A study of 1200 cases of gunshot wounds of the abdomen. Br F Surg 4:679-743.

2. Ogilvie WH (1944). Abdominal wounds in the western desert. Surg Gynecol Obstet 78:225-38.

3. Lavenson ES, Cohen A (1971). Management of rectal injuries. Am f Surg 122:226-30.

4. Stankovic N, Petrovic M, Drinkovic N, Bjelovic M, Jevtic M, Mirkovic D [1996]. Colon and rectal war injuries. F Trauma 40(3suppl): S183-188.

5. Grasberger RC, Hirsch EF (1983). Rectal trauma. A retrospective analysis and guidelines for therapy. Am F Surg 145:795-799.

6. Mangiante EC, Graham AD, Fabian TC (1986). Rectal gunshot wounds. Management of civilian injuries. Am Surg 52:37-40.

7. Miller RE, Sullivan FJ (1976). Rectal wounds incurred in Vietnam. Mil Med 141:764-770.

8. Minard G, Pritchard FE (1998). Rectal trauma: management based on anatomic distinctions. Am Surg 64:1136-41.

9. Velmahos GC, Gomez H, Falabella A, Demetriades D (2000). Operative management of civilian rectal gunshot wounds: simpler is better. World fournal Surgery 24: 114-8.

10. Levine JH, Longo WE, Pruitt C, Mazuski JE, Shapiro MJ, Durham RM (1996). Management of selected rectal injuries by primary repair. Am $\mathcal{F}$ Surg 172:575-578.

11. US Dept.Defence. Emergency war surgery: first United States revision of the emergency war surgery NATO handbook (1997).Chessington. Her majesty's stationery office: 329-331.

12. Rombeau JL, Wilk PJ, Turnbull RB, Fazio VW (1978). Total fecal diversion by the temporary skinlevel loop transverse colostomy. Dis Colon Rectum 21:223-6.

13. Burch JM, Feliciano DV, Mattox KL (1989). Colostomy and drainage for civilian rectal injuries: is that all? Ann Surg 209:

14. Renz BM, Feliciano DV, Sherman R (1993). Same admission colostomy colosure (SACC). A new approach to rectal wounds: a prospective study. Ann Surg 218:279-92; discussion 292-3.

15. Kirby NG, Blackburn G Eds (1981). Field surgery pocket book. London. Her majesty's stationary office: 223.

16. Gonzalez RP, Falimirski ME, Holevar MR (1998). The role of presacral drainage in the management of penetrating rectal injuries. F Trauma 45:656-661.

17. Steinig JP, Boyd CR [1996]. Presacral drainage in penetrating extraperitoneal rectal injuries: is it necessary? Am Surg 62:765-767.

18. McGrath V, Fabian TC, Croce MA, Minard G, Pritchard FE (1998). Rectal trauma: management based on anatomic distinctions. Am Surg 64:11361141 .

19. Tuggle D, Huber PJ (1984). Management of rectal trauma. Am F Surg 148:806-808.

20. Ivatury RR, Licata J, Gundaz Y, Rao P, Stahl WM (1991). Management options in penetrating rectal injuries. Am Surg; 57:50-55.

21. Bostick PJ, Johnson DA, Heard JF, Islas JT, Sims EH, Fleming AW, Sterling-Scott RP (1993). Management of extraperitoneal rectal injuries. $\mathcal{F}$ Nat Med Assoc 85:460-463.

22. Shannon FL, Moore EE, Moore FA, McCroskey BL (1988). Value of distal colon washout in civilian rectal trauma - reducing gut bacterial translocation. F Trauma 28:989-994.

23. Armstrong RG, Schmitt HJ, Patterson LT (1973). Combat wounds of the extraperitoneal rectum. Surgery 74:570-4. 
24. Falcone RE, Carey LC (1988). Colorectal trauma. Surg Clin North Am 68:1307-1318.

25. Franko ER, Ivatury RR, Schwalb DM (1993). Combined penetrating rectal and genitourinary injuries: a challenge in management. $\mathcal{F}$ Trauma 34:347-353.
26. Levy RD, Strauss P, Aladgem D, Degiannis E, Boffard KD, Saadia R (1995). Extraperitoneal rectal gunshot injuries. F Trauma 38:273-277.

27. Thomas DD, Levison MA, Dykstra BJ, Bender JS [1990]. Management of rectal injuries. Dogma versus practice. Am Surg 56:507-10.

\section{Casualties 1 Medic}

\section{What Next...?}

\section{SIMS ${ }^{*}$ : the new standard in triage.}
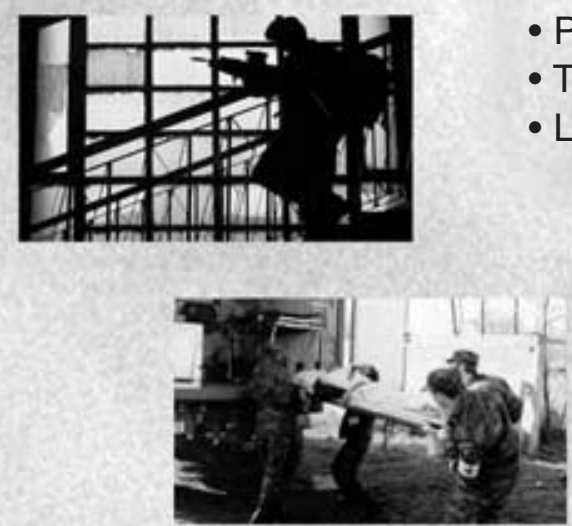

- Effect rapid triage in the toughest conditions.

- Proven to be effective in various theatres of operations.

- The defence medical services standard.

- Lifetime guarantee.

Get your free training now.

Call $+44(0) 1132051715$ for your CD Brochure.

- SIMS - Smart Incident Management System

UK. 